\title{
O Gestor Intermediário bancário e a Cultura do Management
}

\author{
El Gestor Intermediario bancario y la Cultura del Management
}

The Banking Middle Manager and the Management Culture

Elisangela Carpenedo de Mattos

Universidade Federal do Rio Grande do Sul - Rio Grande do Sul-Brasil

Álvaro Roberto Crespo Merlo

Universidade Federal do Rio Grande do Sul - Rio Grande do Sul-Brasil

\section{RESUMO}

O presente trabalho se propõe a apresentar parte dos resultados de uma pesquisa qualitativa, viabilizada por meio de entrevistas semiestruturadas e analisadas à luz da Psicodinâmica do Trabalho, realizada com gestores intermediários, trabalhadores de um banco estatal. Nesta, nos propomos a estudar as articulações entre saúde mental e trabalho, mais especificamente a dinâmica prazer-sofrimento no trabalho de bancários que ocupam cargo de gestores intermediários em um banco, localizado no estado do Rio Grande do Sul, em diversas agências, de diferentes cidades do interior. Apresentamos, neste artigo, as relações entre uma maior ou menor adesão aos novos modos de gestão e as consequências aos trabalhadores. Dentre os achados mais relevantes, consideramos que uma maior adesão à cultura do management produz estratégias defensivas mais efetivas, permitindo aos trabalhadores que continuem trabalhando. Por outro lado, a baixa adesão a esses novos modelos satura as defesas, ocasionando mais vivências de sofrimento e, mesmo, o risco de adoecimento.

Palavras-chave: Saúde do Trabalhador. Psicodinâmica do Trabalho. Trabalho Bancário. Gestores Intermediários.

\section{RESUMEN}

El presente trabajo se propone presentar parte de los resultados de una investigación cualitativa, viabilizada por medio de entrevistas semiestructuradas y analizada a la luz de la Psicodinámica del Trabajo, realizada con gestores intermediarios, trabajadores de un banco estatal. En esta, nos proponemos estudiar las articulaciones entre salud mental y trabajo, más específicamente la dinámica placer-sufrimiento bancario de los trabajadores que ocupan cargo de gestores intermediarios en un banco, ubicado en el estado de Rio Grande do Sul, en agencias diversas, de diferentes ciudades del Interior. En este artículo se presentan las relaciones entre una mayor o menor adhesión a los nuevos modos de gestión y las consecuencias a los trabajadores. Entre los hallazgos más relevantes, 
consideramos que una mayor adhesión a la cultura del management, produce estrategias defensivas más efectivas, permitiendo a los trabajadores seguir trabajando. Por otro lado, la baja adhesión a estos nuevos modelos satura las defensas, ocasionando más vivencias de sufrimiento e incluso el riesgo de enfermedad.

Palabras clave: Salud del Trabajador. Psicodinámica del Trabajo. Trabajo Bancario. Gestores Intermedios.

\begin{abstract}
The present work proposes to present part of the results of a qualitative research, made possible through semi-structured interviews and analyzed in the light of the Psychodynamics of Work, performed with middle managers, workers of a state bank. In this paper, we propose to study the articulations between mental health and work, more specifically the dynamic pleasure-suffering banking experience of the workers who occupy the position of intermediate managers in the bank, located in the state of Rio Grande do Sul, in different agencies, from different cities in the countryside. We report in this article the relations between a greater or lesser adherence to the new modes of management and the consequences to the workers. Among the most relevant findings, we consider that a greater adherence to management culture produces defensive strategies that are more effective, allowing workers to continue working. On the other hand, the low adherence to these new models saturates the defenses, causing more experiences of suffering and even the risk of illness.
\end{abstract}

Keywords: Occupational Health. Psychodynamics of work. Bankemployee. Middle managers.

\section{Introdução}

O presente trabalho é parte do resultado da dissertação de mestrado intitulada "Prazer e sofrimento no trabalho bancário: um olhar sobre o gestor intermediário", a qual se propôs a estudar a dinâmica prazer-sofrimento no trabalho de bancários que ocupam cargo de gestores intermediários em um banco estatal, localizado no estado do Rio Grande do Sul, em diversas agências, de diferentes cidades do interior. A escolha por essa população específica decorreu do fato de que poucos estudos foram realizados, a fim de compreender a dinâmica prazer-sofrimento no trabalho de ocupantes de cargo de gestão (Aguiar, 2013), sobretudo a intermediária. Acrescenta-se que pesquisas de Dejours (1989) apontam maior subjetivação relacionada a níveis hierárquicos mais altos. A gerência média ficaria no lugar que Dejours (1989) chama de nível executivo intermediário, sendo alvo prioritário em caso de conflito que provoca sofrimento. Ainda, segundo o mesmo autor, esses gestores são vítimas da desconfiança e tática do segredo, por parte dos subordinados, além de terem de suportar o confronto e as pressões provocadas pelos executivos que estão acima deles e pela direção da empresa.

Acreditamos ser relevante nos preocuparmos com as relações entre $o$ trabalhador e sua ocupação profissional, sobretudo por conta das transformações ocorridas no mundo do trabalho desde a década de 1980. Eventos como a globalização, que acarretou mudanças rápidas no mercado, associados ao surgimento do Toyotismo, que inaugura $o$ processo de reestruturação produtiva, flexibilização e terceirizações (Aguiar, 2013) foram decisivos nesse processo de remodelação.

A consolidação e propagação do ideário neoliberal fomentaramo surgimento de novas formas de organização, gestão e administração do trabalho, alicerçados no sacrifício da subjetividade em prol da rentabilidade e competitividade. Estas se utilizam da avaliação quantitativa e objetiva do trabalho, que funcionam como mecanismo 
de dominação e intimidação; e da individualização, que conduz ao acirramento da competitividade, incita condutas desleais e a destruição da solidariedade. Em consequência, na mesma via que se verifica o colossal aumento dos lucros e da produtividade, se dá adegradação da subjetividade e do trabalho (Dejours, 2004). Tais articulações nos levaram a pensar em como se vincula a forte adesão aos novos modos de gestão com as possibilidades de resistência e transformação da organização do trabalho.

Consoante ao objetivo proposto, procedemos a uma pesquisa qualitativa, viabilizada por meio de entrevistas semiestruturadas e analisada à luz da Psicodinâmica do Trabalho a qual correlaciona equilíbrio mental e trabalho, visto a centralidade deste na formação da identidade dos sujeitos. Destacamos quese trata de uma identidade em construção, dirigida ao outro, porquanto, sempre trabalhamos em busca de confirmação e realização.

O trabalho reconhecido, além de propiciar a transformação do próprio sujeito, viabiliza a realização no campo social (Cardoso, 2001). Portanto, a partir desta pesquisa-intervenção, buscou-se contribuir de alguma forma, a fim de que os trabalhadores pudessem refletir sobre seu trabalho, produzindo modificações em prol do aumento da satisfação com aquele.

\section{A Gestão e o Trabalho do Gestor}

Etimologicamente gestão $^{1}$ vem do latim gestio, significando ato de administrar, gerenciar; ou, gerere, levar, realizar. Afora sua etimologia, o termo possui inúmeras acepções concernentes às diversas áreas do conhecimento. No decorrer do tempo, entretanto, com as reconfigurações dos modos de produção, os modos de gestão adquiriram conformações diferentes. Por isso,

\footnotetext{
${ }^{1}$ Disponível em:

http://origemdapalavra.com.br/site/palavras/ges tao/.
}

consideramos pertinente explicitar brevemente tais aspectos, tendo em vista seus atravessamentos com o objeto desta pesquisa.

Iniciemos conceituando gestão, nos termos da Administração, consistindo aquela em um processo de coordenar e supervisionar o trabalho de outrem, a fim de que as atividades sejam desempenhadas de maneira eficiente e eficaz (Robbins \& Coulter, 1998). Em nossos termos, gerir pressupõe o ato de orientar o trabalho de terceiros, mobilizandoos a fim de atingir os objetivos estabelecidos, no menor tempo e com mínimos recursos possíveis, impreterivelmente, redundando em lucro.

O gerencialismo, analogamente ao trabalho contemporâneo, não teve origem com o surgimento da humanidade. Acreditamos, pelo contrário, que seu aparecimento tenha estreita relação com a emergência e as mutações advindas do capitalismo. Braverman (1987) explicita que questões relacionadas à gerência teriam surgido um pouco antes da era do capitalismo industrial, no qual expressivo número de operários estavam vinculados a um único capitalista. Entretanto, já nas cooperativas ou reuniões de artesãos, havia necessidade de alguém para coordenar os diversos processos, implicando o aparecimento de uma gerência rudimentar.

Ao surgirem as primeiras fábricas, o artesão ainda decidia como realizar o trabalho, imbuído de seu saber anterior. Portanto, apesar do mesmo não ter mais a propriedade dos instrumentos de produção, ele ainda mantinha certa autonomia e independência que possibilitava resistir ao controle (Motta \& Vasconcelos, 2006).

Com a expansão das indústrias e uma maior variabilidade de processos, as funções de coordenação e concepção carecem de alguém que seja incumbido desse papel - da gerência, sendo, inicialmenteo capitalista, por conta de sua propriedade sobre o capital, imbuído dessa função. Por consequência, este procedia um controle sistemático e minucioso sobre os processos de trabalho. A gerência 
primitiva, do capitalismo industrial, lançava mão da coerção, a fim de habituar os trabalhadores às tarefas e conservá-los trabalhando, impunha horas regulares de trabalho àqueles, enfim, era rígida $\mathrm{e}$ tirânica (Braverman, 1987). A gerência, nesse contexto, encontra-se em construção sendo calcada no controle.

Por volta do final do século XIX, o tamanho das empresas é significativamente maior, e a aplicação da ciência à produção começa a ser sistematizada. Por meiode Frederick Taylor, começam a se delinear os pressupostos da Organização Científica do Trabalho (OCT - abarca os modelos Taylorista e Fordista de gestão organizacional), que visava a redefinir o trabalho para atender aos novos ritmos de produção e imprimir maior velocidade ao processo produtivo, barateando os preços e viabilizando o acesso aos produtos (Braverman, 1987). A torção mais expressiva que Taylor faz em relação à gerência, segundo Braverman (1987), é em relação à efetivação do controle sem precedentes, ao afirmar que a gerência deveria impor, com rigor, o modo de execução do trabalho ao trabalhador. A partir desse momento, a gerência é imbuída de papel central no controle dos processos.

Sendo assim, o ocupante do cargo de gestão passa a ser o detentor do conhecimento, sendo a ele conferida a responsabilidade sobre o pensar, ou seja, separa-se a concepção da execução. $\mathrm{O}$ operário, mero executor de tarefas, além de expropriado de seus instrumentos de produção, foi expropriado do seu saber (Braverman, 1987). Merlo e Lápis (p. 62-63, 2007) asseveram que se consolida assim, "[...] no capitalismo, uma radical separação entre o saber e o fazer; entre a concepção, o planejamento e a execução, entre o trabalho manual dos operários e o trabalho intelectual das gerências".

Destacamos, em relação à tarefa de gerenciamento, acerca do sujeito que realiza tal função, que este se encontra a serviço dos interesses do capitalao prestar-se a efetuar um controle disciplinar sobre os operários.
Concomitantemente, assume um lugar de objeto, visto que viabiliza essa relação. Portanto, simultaneamente, expropria o saber operário e torna-se refém das próprias prescrições de sua função, sendo limitado em sua criatividade. Isso em razão de que, mesmo nas atividades de planejamento, deparamo-nos com uma divisão de tarefas e restrições quanto às interações entre funcionários (Taylor, 1995).

A OCT se expande a partir de 1910 , com a consolidação do Taylorismo, associado aos princípios, métodos e tecnologia de Henry Ford, que ocasionou o recrudescimento da divisão do trabalho e parcelização das tarefas (Merlo \& Lapis, 2007). Para esses autores, "É como se as ordens das chefias e o controle direto [...] com a imposição de tempos e de movimentos de execução, fossem incorporados às instalações (p. 64)".

Salientamos que no modelo Fordista a função do operário, ainda, restringia-se à execução das tarefas, e a posse do conhecimento continuava sob o domínio da gerência. Entretanto, na compreensão de Faria (Jost, Fernandes \& Soboll, 2014), inicia-se a abertura de espaço para os trabalhadores com "[...] algum talento mental [...]" (p. 52), muito embora estes fossem tratados da mesma forma que uma mercadoria. Portanto, podemos inferir que o Taylorismo centrava-se no corpo do sujeito e no controle de seus gestos. O Fordismo, por sua vez, desencadeia um processo, mesmo que incipiente de valorização do saber operário, o que dá mostras de uma aproximação com a função gerencial, tal qual a conhecemos hoje, fundamentada na mobilização subjetiva do trabalhador.

Diante da crise mundial de 1960, principiam-se os sinais de enfraquecimento do Fordismo por sua incapacidade de refrear as contradições intrínsecas ao capitalismo, as quais estavam ligadas, sobretudo, à rigidez. $\mathrm{O}$ enrijecimento se estende tanto no âmbito dos investimentos, sistemas de produção em massa e mercados, quanto em alocações e contratos de trabalho (Harvey, 1992). A crise que 
atingiu os países capitalistas facilitou o surgimento, a partir dos anos 1970, de um novo modelo de organização do trabalho, chamado de modelo japonês ou Toyotismo, o qual inaugura a era da acumulação flexível (Harvey, 1992; Merlo \& Lapis, 2007). Na compreensão de Merlo e Lapis (2007), novas formas de organização do trabalho e da produção emergem. Essas novas configurações decorrem no intuito de elevar a produtividade, reduzir custos e promover um efetivo controle de qualidade, surge a empresa enxuta, com menor contingente de trabalhadores, possibilitado pelos avanços da microeletrônica. Dissemina-se o ideário Toyotista.

Com o propósito de atender à demanda imposta por essas novas formas de organização do trabalho e da produção, tornase imperativa a emergência de um novo trabalhador. Frente a essa nova realidade, o envolvimento mais efetivo do trabalhador é requerido. Este, segundo Merlo e Lapis (2007), deve ser mais qualificado, ter capacidade de raciocínio, bom relacionamento interpessoal, estar apto a manejar diferentes equipamentos e desempenhar várias operações, motivado e engajado - o conceito de colaborador manifesta-se. Antunes (2014) sustenta que esse sujeito de aspecto mais participativo - instigado pelo trabalho em equipe, em células de produção ou times de trabalho - na verdade, tem interiorizadas as formas de reificação (envolvimento, colaboração, competências, dentre outras), acentuando a degradação no trabalho e colaborando para o incremento da precarização e perda de direitos sociais.

Gaulejac (2007) sanciona a alegação sobre a interiorização das formas de reificação ao declarar que o poder gerencialista substitui as ordens e proibições por procedimentos e princípios interiorizados, consoantes à lógica da organização. Nesse ponto, reside a sutileza do controle intrínseco, exercido sobre os trabalhadores. A esse respeito, Barreto e Heloani (2014) contribuem afirmando que se tratam de técnicas mais sutis de controle, que
"[...] requer uma política de envolvimento narcísico dos colaboradores e seus "feitores" (p. 55)", a qual implica a manipulação de sua subjetividade. Em complementação, Bottega (2014) assevera que a sujeição infligida não se restringe à subjetividade, estende-se aos campos afetivo e psicológico também.

Tem-se, então, que os trabalhadores "[...] se envolvem mais com a organização e canalizam sua energia vital produtiva para a consecução dos objetivos organizacionais" (Motta \& Vasconcelos, 2006, p. 64). Diante disso, surge a gerência participativa, horizontalização das empresas, maior comprometimento das pessoas com a organização, ou seja, tratam-se dos pressupostos do Toyotismo (Motta \& Vasconcelos, 2006). Chegamos, assim, ao gestor contemporâneo.

Parece-nos, no Toyotismo, haver, em certa medida, um entrelaçamento na produção de subjetividade de gestores (assalariados) e trabalhadores, que não havia nos demais modelos, visto justamente a horizontalização das empresas, exigência de maior envolvimento e participação nas decisões. Encontramos para isso respaldo na afirmativa de Gaulejac (2007), no tocante ao gerenciamento intermediário, que com frequência é excluído dos processos decisórios, só restando a estes o caráter ambíguo da gestão, pois se, por um lado, partilham do sofrimento dos assalariados, por outro, são responsáveis pela violência imposta a estes.

Gaulejac (2007) explicita que a gestão gerencialista é apresentada como um progresso, em relação ao sistema disciplinar, por meio da primazia do lucro, do consentimento como construção e da mobilização subjetiva. Chanlat (2011) nos traz importante contribuição para compreender o papel do gestor nas organizações contemporâneas ao afirmar que este é sujeito, mas também objeto, portanto, da mesma forma que possui ingerência sobre seu trabalho e de seus subordinados, também é submetido às 
interferências de seus superiores, colaboradores, clientes, dentre outros.

\section{Metodologia}

A metodologia utilizada na presente pesquisa está baseada nos pressupostos teórico-metodológicos da Psicodinâmica do Trabalho (PdT), tendo sido adaptada em sua execução e utilizada para a compreensão dos temas abordados nas entrevistas. Os sujeitos da pesquisa são bancários, os quais ocupam cargo de gestão intermediária, totalizando uma amostra de 16 pessoas.

Em relação ao gênero, a amostra se caracterizou por oito participantes do sexo feminino e oito do sexo masculino. A idade dos participantes variou de 29 a 52 anos. Quanto à formação profissional, dez bancários são pós-graduados, um estava cursando MBA, quatro são graduados e um possui curso técnico.

No que diz respeito ao tempo como bancários, a variação foi de seis a 27 anos de banco, sendo que desses, apenas um trabalhou em outra instituição financeira, antes de trabalhar no banco $\mathrm{X}$. No que tange ao tempo como gestor, este oscilou entre oito meses e 20 anos de cargo. Destes, um dos gestores já havia ocupado cargo análogo em outra instituição bancária. A carga horária semanal formal para todos eles é de 40 horas.

O objetivo da pesquisa, conforme mencionado anteriormente, foi discutir os entrelaçamentos no que tange à adesão à cultura do management $\mathrm{e}$ às possibilidades de resistência aos modos de organização do trabalho vigentes. Tendo em vista a impossibilidade de quantificar tais fatores, visto seu caráter subjetivo, utilizamo-nos da pesquisa qualitativa, como ferramenta de trabalho, pois segundo Cruz (2009), esta permite "[...] entender um fenômeno específico em profundidade" (Cruz, 2009, p. 65). Acreditamos que o método escolhido está intimamente relacionado ao objeto de estudo, pois a pesquisa qualitativa consente estudar a complexidade e efetuar o aprofundamento dos motivos pelos quais determinado fenômeno acontece.

Consoante a tal proposta, salientamos, em relação à Psicodinâmica do Trabalho, que o material de pesquisa a ser analisado é a fala, ou o "[...] comentário verbal [...]" (p. 108), conforme afirma Dejours (2004a). Não é a objetividade dos fatos que interessa, mas sim a versão dos trabalhadores sobre estes, daquilo que é construído coletivamente, sejam temas consensuais ou aqueles objetos de discussões contraditórias entre o grupo de trabalhadores. Destacamos que a Psicodinâmica não preconiza modificações ou recomendações no local de trabalho, após o levantamento dos dados, mas objetiva que os próprios trabalhadores possam pensar e intervir em seu trabalho. Nesse sentido, é descrita por Dejours (2004a) como um modelo de pesquisa-ação, em que a reflexão em si pelo coletivo de trabalhadores provoca mudanças. Nessa perspectiva, não se trata apenas de coletar dados, visto que Dejours acredita que os fatos não existem por si só, justificando tal impossibilidade. Preconiza-se a construção coletiva, obrigatoriamente, validada pelos mesmos.

A pesquisa inicial foi realizada a partir de levantamento bibliográfico sobre o tema, objeto deste estudo, visto os inúmeros estudos que foram desenvolvidos, sobretudo nos anos 1990, a respeito das consequências da reestruturação produtiva no trabalho bancário, logo era necessário buscar um diferencial a ser focalizado na pesquisa. Para isso, examinamos livros e artigos científicos que versassem sobre o tema, a fim de encontrar pontos de escassez que necessitassem maior aprofundamento, tendo encontrado poucos estudos focalizados nos gestores intermediários. Posteriormente, realizamos a pesquisa de campo, com as devidas adaptações à PdT.

Nossa proposta inicial consistiu em realizar grupos, com gestores intermediários de determinada instituição bancária. Entretanto, inúmeros fatores contribuíram para que a metodologia tivesse que ser adaptada, 
nesse caso, utilizando-se entrevistas individuais semiestruturadas com esses gestores intermediários. Em relação às questões utilizadas, a fim de atingir os objetivos propostos, indagamos os sujeitos sobre a sua trajetória profissional, rotina como gestor, incluindo pontos positivos e negativos, reconhecimento e significado do trabalho, convívio com os colegas, dentre outras.

Sobre as fases da pesquisa em Psicodinâmica, esclarecemos que a mesma abarca a pré-pesquisa, a qual inclui a formação do grupo de pesquisadores; a pesquisa propriamente dita, refere-se à pesquisa de campo em si, consistindo na análise da demanda, do material de pesquisa, as entrevistas, a caracterização dos trabalhadores que dela participaram, bem como, a observação clínica; a interpretação do material produzido e a validação (Dejours, 2004a). Com relação a essas fases, chamamos a atenção, conforme Merlo e Mendes (2009), para a utilização da PdT como método, o qual não se restringe à reprodução de passos técnicos a fim de coletar dados, mas colocar em prática seus pressupostos, compreendendo os efeitos da escuta do sofrimento nos processos de subjetivação, assim como na saúde mental dos trabalhadores.

Quanto aos procedimentos éticos, o projeto da presente pesquisa foi aprovado pelo Comitê de Ética do Instituto de Psicologia Social e Institucional da UFRGS sob $\mathrm{n}^{\circ}$ 1.172.508, conforme parecer consubstanciado do CEP favorável à realização do estudo. Foram seguidos todos os preceitos éticos da pesquisa com seres humanos preconizados pela legislação brasileira, tendo como fundamento a Resolução 466/2012 do Conselho Nacional de Saúde (Brasil, 2012).

\section{Resultados e discussão}

Os resultados a serem discutidos neste item estão relacionados ao último objetivo específico, da já mencionada dissertação de Mestrado que originou o presente artigo. Objetivo este que ensejou apurar as diferenças de percepção de prazer e sofrimento no trabalho dos gestores intermediários entrevistados, os quais tinham de oito meses a 20 anos no cargo.

As pesquisas nos mostraram que a maior introjeção dos valores relacionados aos novos modos de gestão, também conhecidos por poder gerencialista ou cultura do management, permite que os gestores consigam produzir estratégias de defesas mais eficientes, oportunizando mais vivências de prazer. Cultura esta que, de acordo com Gaulejac (2007, p. 40), “[...] é uma ideologia que traduz as atividades humanas em indicadores de desempenhos, e esses desempenhos em custos ou benefícios". A baixa adesão a esses novos modelos, por sua vez, satura as defesas, até mesmo por conta das dificuldades de cooperação e de coletividade, ocasionando mais vivências de sofrimento e mesmo o risco de adoecimento. Essas constatações ratificam a assertiva de Dejours (2007), acerca da característica secundária da empresa atual (a primeira é o lucro), ou seja, não se trata da produção ou do trabalho. "O que caracteriza é sua organização, sua gestão, seu gerenciamento" (p. 41).

Para Gaulejac (2007), as relações de poder no âmbito das empresas se modificam no instante em que a lógica financeira se sobrepõe à lógica de produção. A partir daí, as pessoas passam a ser vistas como recursos (a serviço da empresa), consequentemente, custos a serem reduzidos de qualquer maneira (Gaulejac, 2007; 2011). Por outro lado, os sujeitos, dentro dessa lógica, são rentabilizados. Isso quer dizer que cada sujeito deve ser responsável por gerir sua vida, fixando objetivos, avaliando e aprimorando seu desempenho, a fim de rentabilizar até mesmo seu tempo (Gaulejac, 2007).

Nesse sentido, "O trabalho é
apresentado como uma experiência
interessante, enriquecedora e
(Gaulejac, 2007, p. 113). Na qual é
imprescindível que os trabalhadores sintam-se
responsáveis pelos resultados, podendo assim,


desenvolver seus talentos, competências e criatividade. A mobilização individual é indispensável, em decorrência disso, encontramos uma cobrança interna muito forte, bem como, a autorresponsabilização frequente. A questão da ascensão profissional está conectada a esses dois fatores, visto a progressão na carreira implicar a conquista do reconhecimento simbólico e material, remetendo à construção da identidade do sujeito (Gernet \& Dejours, 2011).

[...] se eu não "tô" satisfeito com o que eu ganho, eu tenho como crescer, tenho. Hoje a gente sabe que tem. Então, "ah, mas eu queria ganhar mais". Então... mas eu tenho espaço pra crescer, eu não estou limitado, hoje, aqui. Então basta... tá em mim, tá em mim, eu posso sair fora, eu posso ir pra outra cidade, eu posso...então assim, eu acho muito positivo isso. (Informação verbal).

A questão mesmo do reconhecimento do teu trabalho, porque hoje a tua carreira, basicamente depende de ti. Então, se tu pretende crescer profissionalmente dentro do banco, depende em grande parte do teu esforço. (Informação verbal).

Então depende de ti em termos de aperfeiçoamento, tu buscar, tu fazer uma pós, as certificações, enfim, o banco te dá oportunidades de crescimento. (Informação verbal).

Gaulejac (2007) nos chama a atenção que na lógica gerencialista o desemprego não é encarado como decorrente do chamado desemprego estrutural, preconizado pelos neoliberalistas. É tratado como uma falha de empregabilidade de parte da população, a qual não consegue se adaptar às necessidades da empresa. Analogamente, entendemos que os entrevistados, ao introjetar vigorosamente os ideais gestionários, não conseguem compreender que mesmo havendo no banco espaço para o crescimento, não é possível que todos consigam ocupar um cargo de gestão.
Mesmo os que se dispuserem a "fazer o que o banco quer" ou se esforçarem, ou estudarem conforme preconizado pelos novos modos de gestão, que para manter-se empregado e rentável é preciso se qualificar e gerenciar a carreira (Carrasqueira, Moraes\& Soboll, 2014) - a nosso ver é insuficiente. Talvez alguém, insuficientemente mobilizado, faça essa leitura.

As pessoas que tem um QI (Quem Indica), que tem uma amizade dentro da empresa, elas conseguem subir. Se tu não tiver uma amizade lá dentro, que seja uma amizade externa, não só interna, que tu leve isso aí pra tua vida pessoal, lá fora, que "teja" algum relacionamento externo, tu não consegue ir. Só ser profissional hoje, tu não consegue nada, tu te pósgraduar, tu pode ter graduação, tu pode ter os cursos e tudo. (Informação verbal).

A empresa é colocada como objeto de investimento, na qual cada trabalhador é convidado a se dedicar. Alia-se a isso a ideia de comprometimento, que leva a crer que o sucesso da empresa depende do empenho de cada sujeito (Gaulejac, 2007). Logo, a empresa é vista como uma catedral que concede a salvação à alma do trabalhador (Andreazza, 2008). Então, no geral, a mobilização pessoal é intensa, conforme demonstram os comentários.

Então a pressão que a gente sente é ali no dia. E tu te sente assim, a pressão e aquele compromisso de fazer alguma coisa, eu tenho que ajudar, eu tenho que fazer a minha parte, eu sou responsável por este setor, então. Mas sempre de cima pra baixo. E interna também, é normal. (Informação verbal).

Porque o maior problema, além da exigência externa, a pior delas é a exigência interna. Então, eu sempre consegui construir a minha carreira, indo muito bem, não sendo a melhor, 
mas estando entre as melhores. E agora estou com uma certa dificuldade pra isso, então a minha exigência interna está sendo muito séria. E aí que tá me dando esses problemas mesmo, que eu acho que é isso que tá me ocasionando. Com essa dificuldade agora pra falar, essa ansiedade, que é o que eu tenho que estar tratando. (Informação verbal).

A mobilização pessoal ou o engajamento, imprescindíveis ao atingimento dos objetivos da empresa, ocorrem por meio de um contrato psicológico e ideológico visando àsedução dos indivíduos (Carrasqueira et. al., 2014). A empresa é personificada, e sobre ela os empregados devem canalizar sua implicação, mas eles esperam por reconhecimento (Gaulejac, 2007). Sendo assim, cada vez é preciso trabalhar mais e melhor, no intuito de receber o reconhecimento e obter ganhos no registro de sua identidade (Carrasqueira, et. al., 2014).

A questão do reconhecimento, eu não posso esperar que a empresa vai me levar até o final, vai me botar lá na cabeça. Eu tenho que sair, eu também tenho que fazer. Então esse reconhecimento, depende um pouquinho de mim, um pouquinho não, depende bastante, né. (Informação verbal).

Na lógica da racionalidade econômica, Enriquez (2006) afirma que os sujeitos devem se identificar com as empresas e idealizá-las, sobrepondo os valores organizacionais aos seus, submetendo-se e acreditando serem responsáveis pelo sucesso da organização. Sendo que, em caso de fracasso, é ao sujeito que a culpa será imputada, facilmente descartados, mesmo com todo esforço dispendido. É, a partir dessa lógica da introjeção da responsabilidade, que nossos entrevistados exemplificam a cultura do management, sentindo-se sempre culpados, em falta, em caso dos seus esforços serem quantificados objetivamente, não conseguirem atender ao que foi solicitado.

\begin{abstract}
É isso que te causa incompetência. Porque dai tu fica pensando: "será que sou eu que não consigo, será que...?" Isso que te causa essa sensação ruim de: "será que eu "tô" no lugar certo? Será que eu cheguei aqui por méritos ou caí aqui de paraquedas, que eu não "tô" sabendo o que fazer?” (Informação verbal).
\end{abstract}

Então "O homem tem, cada vez mais, a solidão como companheira" (Enriquez, 2006, p. 6). Seligmann-Silva (2011) defende que o individualismo foi incutido nos sujeitos e nas culturas no intuito de iniciar um processo de dissolução do social. Este pode ser percebido no mundo do trabalho, na postura da maioria dos trabalhadores, decorrentes dos novos modos de gestão e produção correntes. Diante daimpossibilidade de compartimentalização dos sujeitos ou da vida destes, do mesmo modo que no trabalho, cada vez com mais intensidade, manifesta-se o individualismo.

Podemos inferir que individualismo exacerbado faz surgir, conforme Benjamim (2012, p. 3), “[...] uma existência que se basta a si mesma, [...]". Esta leva os sujeitos a um extremo isolamento, assim como sua imersão em um mundo particular e privado (Gagnebin, 2012). Se, em outros tempos, a experiência coletiva estava garantida por meio do trabalho (Gagnebin, 2012), hoje o que vivenciamos, por exemplo, é o desmantelamento desses coletivos de trabalho, que têm como consequência a desconfiança, falta de solidariedade e hipocrisia, dentre outros (Dejours, 2008; Gernet \& Dejours, 2011). Weber e Grisci (2010) e Seligmann-Silva (2011) corroboram essa ideia, afirmando que a intensificação do individualismo traz consigo a vulnerabilidade, que nos sujeitos se transforma em fragilidade psíquica, isolamento e solidão.

No comentário "Não existe mais aquela equipe, o senso de equipe, em função 
desse carreirismo", é possível perceber o individualismo exacerbado pela concorrência entre os pares, assim como o que segue demonstrao isolamento pela falta de confiança nas pessoas:

A relação no banco é tranquila mas, tu tem que colocar uma vírgula nesse tranquila, tu não pode confiar em ninguém [...] Mas eu sei que eu não posso confiar em uma única pessoa, que esteja trabalhando no banco, em nenhuma. Eu achei que tivesse alguém em quem eu pudesse confiar, hoje eu sei que não tem nenhuma. (Informação verbal).

Ao mesmo tempo em que os trabalhadores compreendem a importância do trabalho coletivo, até mesmo porque o poder gerencialista o fomenta, sendo condição trabalhar sempre em prol do alcance dos objetivos da organização (Gaulejac, 2007). Por outro lado, há uma opção por realizar o trabalho de maneira solitária, responsabilizando-se pelos resultados, concomitantemente impondo uma forma de trabalhar aos demais membros da equipe. Isso porque, conforme Weber e Grisci (2010), não há espaços para debates ou reflexões coletivas, no que tange às dificuldades das chefias intermediárias.

Assim, a gente procura trabalhar sempre em conjunto, mas não tem assim como tu não puxar pra ti. Tu tem que puxar, administrar e assim a responsabilidade é tua, a cobrança é em cima de ti. Então, quer dizer, tu puxa os colegas pra te ajudar, na verdade, e claro, pede a participação deles, mas na verdade quem acaba...e isso eu procuro me policiar, mas acaba parece que fica centralizador. (Informação verbal).

Os comentários verbais que seguem denotam, em nossa opinião, resquícios de trabalho em equipe. Entretanto, compreendemos que os trabalhadores estão por si mesmos, pois em geral não há espaço para reflexão sobre o trabalho em conjunto com os colegas - cada um faz o trabalho do seu jeito. Quando é possibilitado aos trabalhadores falar sobre o trabalho que realizam, frequentemente é no intuito de se apropriar do saber desse trabalhador (Antunes, 2002) ou, em outros casos, tem apenas caráter informativo ("discutir" sobre as metas a serem atingidas e como fazê-lo). Até porque, num mundo de extrema competitividade no qual estamos inseridos, refletir sobre melhores formas de trabalhar implica um risco: o risco de se expor aos demais, expor as dúvidas, as fraquezas, algo que "poderá ser usado contra" o trabalhador na próxima promoção ou a serviço de uma demissão.

\begin{abstract}
Geralmente eu tento incentivar eles a darem sugestões, mas a maior parte das estratégias acabam partindo da gerência média da agência em si, com o gerente geral. A gente constrói as estratégias, delega funções pra eles [...]. (Informação verbal).
\end{abstract}

Então, quase que diariamente, eu chamo o meu assistente e nós definimos, bom... hoje nós temos que fazer determinado número, e daí nós definimos um público pra ser contatado [...] pra venda, no caso. (Informação verbal).

A cooperação como vimos, quando ocorre, é mais no sentido de trocar informações para o atingimento das metas, sobre quais estratégias os colegas estão utilizando e que estão funcionando, até para poder "medir" o próprio desempenho. Dejours (2004a) propõe que não é possível prescrever a cooperação, assim como a ética nas relações de trabalho reside na prática e, não, nos procedimentos. Dessa forma, acreditamos que a cooperação não ocorre, mais efetivamente, por conta do clima de desconfiança decorrente da competitividade no espaço laboral, a qual impede que uma verdadeira discussão acerca do trabalho seja empreendida a fim de realizar a atividade deontológica (Traesel \& Merlo, 2014). Ou seja, ela consiste em estabelecer 
normas e acordos para a realização do trabalho real, isso traz prejuízos tanto à organização do trabalho, quanto à saúde do trabalhador.

A gente sabe que tem que vender de tudo, mas algumas coisas são foco no mês. Então, essas que são foco no mês, a gente troca uma ideia entre colegas de como facilitar, ou algum colega descobriu uma maneira de identificar aquele público mais fácil, aquele público alvo. Então a gente troca ideias, [...]. Mas agora tá bem tranquilo até, temos um grupo bom, porque é muito importante a união, de estar junto e do auxílio mútuo. (Informação verbal).

A eficácia e o produtivismo são imperativos para sobreviver no mercado. Assim como a competitividade é vista como algo natural, que necessita adaptação (Gaulejac, 2007). A competitividade é vista como consequência da esfera trabalhista, cabendo ao trabalhador superar seus rivais, no entanto, não perdendo o foco de sua trajetória profissional, a qual deve ser de sucesso (Carrasqueira et. al., 2014).

[...] e muito carreirismo de gente intermediária, gente que só pensa em subir na carreira e não em viver bem, em ter um ambiente bom. Existem paliativos, como encontros de funcionários, palavras bonitas que não se traduzem na realidade.

A ideologia do sucesso faz com que cada sujeito queira ser o melhor. Logo, não é suficiente ser bom e fazer bem o trabalho, é imperativo fazê-lo sempre melhor, acima da média. O que faz com que o sucesso seja uma imposição e o ideal de perfeição, leve à competição sem precedentes (Gaulejac, 2007). É a ditadura do sucesso (Carrasqueira et. al., 2014), este que muitas vezes precisa ser alcançado a qualquer preço, independente dos danos causados à própria saúde ou à dos outros, ou mesmo das consequências para vida pessoal, para a família, conforme relatos a seguir.
[...] pra eles o que importa é só negócio, porque negócio? $O$ banco vive só disso, e realmente tem que priorizar negócio. Mas o negócio só é possivel, quando ele têm estrutura pra fazer o negócio. E o negócio é bom pro gerente por que? Porque ele vai apresentar números e ele vai crescer. Então não importa se ele tá causando sofrimento pra alguém ao diminuir o seu quadro, o que importa é que ele vai ter número e ele vai crescer. (Informação verbal).

Então, não existe uma carreira do nada, tu vai ter que abrir mão da vida pessoal, tu vai ter que abrir mão da tua cidade, tu vai ter que mudar de cidade, tu vai ter que às vezes até passar por cima de algum princípio e coisa e tal, focar em sua meta, às vezes deixar de lado até o bom atendimento, aquela atenção especial que tu dá pro cliente. (Informação verbal).

Além da ideologia do sucesso, Gaulejac (2007) ainda refere o culto ao desempenho, que tem atravessamentos com a exacerbação da competitividade, visto também colocar os trabalhadores em uma disputa incessante, na busca por mais, "[...] sempre mais" (p. 91). Trabalhar já não consiste em realizar uma tarefa em um tempo pré-definido, os trabalhadores contemporâneos realizam desempenhos. A concorrência instiga voltar o olhar para o desempenho dos trabalhadores, em consequência, a crítica sobre a lógica organizacional é enfraquecida.

Visto a tarefa já não ser mais executada em determinado tempo, o tempo de trabalho também não tem mais limitações. Como são realizados desempenhos, os horários de trabalho são insuficientes, por isso, cada vez mais o tempo de trabalho irá invadir o tempo de vidado trabalhador. Além disso, com os contínuos enxugamentos, que têm como consequência o aumento do volume de trabalho e diminuição de efetivo para o 
trabalho, maior temor irá ocasionar no trabalhador, sendo que a preocupação com o trabalho também é considerada tempo de trabalho. Isso pode ser exemplificado, quando o trabalhador afirma que "Até, falando do banco dá pra descontrair, daí aquilo que é sério lá no momento do trabalho vira piada, na hora do happy hour." Entendemos que, nesse caso, mecanismos de defesa são utilizados como paliativo para não mostrar a intensa mobilização psíquica da trabalhadora, em relação ao trabalho, uma vez que mesmo, em momentos de descontração, o assunto é o trabalho.

O que os trabalhadores demonstraram, em sua maioria, é que há um esforço intenso para que as preocupações do trabalho não invadam os momentos de descanso e lazer. Porém, observamos que se trata de um exercício que não é fácil, pois eles acabam pensando ou sonhando com trabalho, referem mesmo acordar à noite com a solução de um problema.

E final de semana eu gosto de ir pra fora pra descansar, porque aí tu desliga de tudo. De repente aquele cliente que brigou contigo, se tu fica na cidade tu já lembra daquilo ali ou tu tá no mercado alguém te pergunta alguma coisa de banco, então eu gosto de ir pra fora, eu vou pra fora e é a maneira que eu acho de descansar. (Informação verbal).

[...] às vezes acordo de madrugada, lembrando que esqueci de fazer alguma coisa, por isso que eu tenho caderninho e caneta do lado, porque lembra, a gente trabalha de noite também, lembra de alguma coisa que esqueceu ou de alguma coisa que tinha prometido pro cliente que ia dar uma resposta e não deu, esqueceu. Aí, essas coisa a gente lembra de noite, quando tá dormindo. Aí anota. E aí tu acaba já com aquilo, eu tenho que fazer isso. (Informação verbal).
Carrasqueira et. al. (2014) referem sobre o risco da mobilização excessiva por conta de alto grau de engajamento, o qual pode levar à sobrecarga de trabalho. Isso, porque o tempo de trabalho ultrapassa as fronteiras deste, passando por ocupar espaços que antes eram destinados à família ou ao lazer.

$O$ que a gente trabalha no banco e às vezes, eventualmente fora, não é uma coisa assim, toda hora, mas eventualmente fora do horário de trabalho, mas não sai nada fora assim do que tu pode fazer e acho que deve fazer, porque faz parte, é uma sequência. (Informação verbal).

As novas técnicas de gerenciamento, voltadas para a acumulação flexível e maximização dos lucros, provocam a exacerbação da competição, reforçando o individualismo (Seligmann-Silva, 2011), conforme já citado. Ainda em relação àquelas, dentre as mais amplamente utilizadas pelas empresas contemporâneas, destacamos, conforme Gaulejac (2011), que as mesmas colocam o sujeito frente a um sistema paradoxal - é a chamada Nova Gestão Paradoxal- regido por injunções paradoxais, ou seja, mensagens conflitantes. Conforme comentários emitidos por alguns dos trabalhadores, esse fato é percebido e causa estranheza. $\mathrm{O}$ que nos parece, pelas entrevistas, é que os trabalhadores aqui lançam mão da clivagem, como estratégia defensiva, pois ao mesmo tempo em que aderem aos desígnios da empresa, internamente resistem à cooptação.

Tem essa questão muito forte de cobrança, cada vez mais [...] por um lado eles te cobram que tu tem que cumprir aquelas metas, por um outro, por outro lado te cobram que tu tem que cumprir com responsabilidade socioambiental, que seria não forçar ou vender pro cliente aquilo que ele realmente precisa.(Informação verbal). 
E essa sinuca de bico eu vejo como um ponto negativo também. Tu tá sempre sendo testado, mas se tu não fizer, tu é punido. Tu não pode ser punido por não atingir o número. Tu tem que ter é incentivo de ir atrás. E aí valorizar essas pessoas que tão indo atrás. (Informação verbal).

Gaulejac (2011) também refere que a gestão paradoxal tem suas bases em um sistema de comunicação que emite mensagens contraditórias e que impedem qualquer saída. O trabalhador se vê forçado a obedecer duas demandas totalmente incompatíveis, ficando impossibilitado de responder a qualquer uma delas de forma satisfatória. O sujeito se vê sem saída, pois não pode optar por atender somente auma das exigências, ambas são obrigatórias e antagônicas. "O que quer que faça, ele pode ser pego em erro [...]" (Gaulejac, 2011, p. 86). Como no exemplo a seguir, do correio interno que passa mensagens dúbias, o banco também possui um Código de Ética, o qual obrigatoriamente todo funcionário deve conhecer, no qual há os preceitos éticos a serem seguidos por todos, mas na prática aquilo que é requerido do sujeito no dia a dia, inúmeras vezes entra em conflito com o que está formalizado nesse código.

[...] é muito engraçado quando mandam um correio interno do banco te cobrando que seja vendido previdência, e no final colocam uma frase de sei lá eu quem, que já morreu já faz tempo, porque normalmente as frases que colocam os caras já faleceram: "faça uma venda consciente", "não faça espuma". [...] o banco tá te cobrando, tu tem que dar um jeito de fazer, mas faça uma venda consciente. Tu não fez, olha eu não fiz porque eu tinha que fazer uma venda só se fosse consciente, tu é punido por isso, tu não fez. (Informação verbal).
O trabalhador, assim, se vê num beco sem saída, uma vez que para atender de forma satisfatória aos projetos da empresa deve transgredir regras, as quais a própria organização formal do banco determina que não podem ser desrespeitadas. Também se vê em constante angústia, pois receberá punição independente do que fizer, seja pelo não atingimento de metas, seja pela venda que não observa a responsabilidade socioambiental. Isso traduz a frase de Gaulejac (2011, p. 91), quando afirma que "O discurso gerencial escorado em paradigmas objetivistas, funcionais e utilitaristas desemboca em exigências insensatas, disfuncionais e inúteis".

\section{Considerações finais}

A partir da experiência de escuta desta pesquisadora, não como psicóloga, mas como colega-trabalhadora-bancária, foi construída uma hipótese acerca das relações entre o tempo de gestão e a maior ou menor motivação no trabalho. Dentre os achados que consideramos mais relevantes neste estudo, está a desconstrução de nossa hipótese inicial, que preconizava que gestores com maior tempo no cargo teriam uma visão mais negativa do trabalho, ocasionando desmotivação e sofrimento. Por outro lado, gestores nomeados a menos tempo ou que tivessem mais mobilidade veriam o trabalho no banco de maneira mais positiva. Daquilo que efetivamente nos deparamos e que está em acordo com o que refere Andreazza (2008), sempre existe um descompasso entre aquilo que buscamos e o que encontramos e, nesse interstício, há uma potência. Constatamos, pois, que esses trabalhadores aderem intensamente à cultura do management, e isso lhes proporciona a construção de estratégias defensivas mais efetivas, mesmo sendo individuais, que os permite continuar trabalhando, seja em condições hostis.

Aqueles que conseguem "descolar" um pouco da lógica dos novos modos de gestão, visto estarem submetidos a estes através do exercício do poder, conseguem em certa medida possibilitar a si mesmo exercer sua 
liberdade, no sentido foucaultiano do termo ${ }^{2}$. Ou seja, a liberdade, caso se propiciem condições, pode ser utilizada de forma potente para efetuar modificações na forma de organização do trabalho. Nesse sentido, acreditamosque, mesmo não oportunizando um espaço coletivo de discussão entre os participantes da pesquisa, conforme preconizado pela PdT, viabilizamos um espaço para que fosse possível a esses trabalhadores pensar sobre o seu trabalho e talvez produzir, de certa forma, o empoderamento dos mesmos. Acreditamos que espaços como estes necessitam cada vez mais de viabilização, visto seu potencial de reflexão acerca das condições de trabalho, bem como da produção de modificações na melhora das condições destas.

\section{Referências}

Aguiar, V. B. (2013). Psicodinâmica da relação gestor-equipe: análise do prazersofrimento no trabalho em uma organização pública. Dissertação de Mestrado, Programa de Pós-graduação do Instituto de Psicologia. Universidade de Brasília, Brasília, DF.

Andreazza, J. P. (2008). O trabalho contemporâneo e os efeitos da flexibilização no trabalho do setor administrativo. Dissertação de Mestrado, Programa de Pós-graduação em Psicologia Social e Institucional do Instituto de Psicologia. Universidade Federal do Rio Grande do Sul, Porto Alegre, RS.

Antunes, R. (2002) (6). Adeus ao trabalho? Ensaio sobre as metamorfoses $e$ a centralidade do mundo do trabalho. São Paulo/SP: Boitempo.

Antunes, R. (2014). Desenhando a nova morfologia do trabalho e suas principais

\footnotetext{
${ }^{2} \mathrm{O}$ poder só se exerce sobre "sujeitos livres", enquanto "livres" - entendendo-se por isso sujeitos individuais ou coletivos que tem diante de si um campo de possibilidade onde diversas condutas, diversas reações e diversos modos de comportamento podem acontecer (FOUCAULT, 1995, p. 244). Portanto, o exercício de liberdade só é possível, quando há certo grau de exercício do poder.
}

manifestações. In: Merlo, A. R. C., Bottega, C. G., \& Perez, K. V. (Orgs.). Atenção à saúde mental do trabalhador: sofrimento e transtornos psíquicos relacionados ao trabalho. Porto Alegre: Evangraf, p. 30- 51.

Barreto, M., \& Heloani, R. (2014). Assédio moral como instrumento de gerenciamento. In: Merlo, A. R. C., Bottega, C. G., \& Perez, K. V. (Orgs.). Atenção à saúde mental do trabalhador: sofrimento $e$ transtornos psíquicos relacionados ao trabalho. Porto Alegre: Evangraf, p. 30- 51.

Benjamin, W. (2012). Experiência e Pobreza. In: Magia e Técnica, Arte e Política. Ensaios sobre literatura e história da cultura. Obras Escolhidas I. São Paulo: Brasiliense.

Bottega, C. G. (2014). A hora do "bom dia" apontamentos para a composição da linha de cuidado em saúde do trabalhador no sistema único de saúde (SUS). In: Merlo, A. R. C., Bottega, C. G., \& Perez, K. V. (Orgs.). Atenção à saúde mental do trabalhador: sofrimento e transtornos psíquicos relacionados ao trabalho. Porto Alegre: Evangraf, p. 244 - 268.

Braverman, H. (1987) (3). Trabalho e capital monopolista: a degradação do trabalho no século $X X$. Rio de Janeiro/RJ: Editora Guanabara S.A.

Brasil. (2012). Ministério da Saúde. Conselho Nacional de Saúde. Resolução no 466/2012. Diretrizes e normas regulamentadoras de pesquisas envolvendo seres humanos. Brasília, DF.

Cardoso, M. R. (2001). Christophe Déjours. Ágora: Estudos em Teoria Psicanalítica, 4(2), 89-94. DOI: https://dx.doi.org/10.1590/S151614982001000200007.

Carrasqueira, F., Moraes, R. M. De, \& Soboll, L. A. (2014). Desejo de carreira, flexibilidade e engajamento: o perfil do trabalhador de sucesso na Cultura do Management. In: Soboll, L. A., \& Ferraz, D.L.da S. (Orgs.). Gestão de Pessoas: armadilhas da organização do trabalho. São Paulo, SP: Atlas, p. 217-232.

Chanlat, J. (2011). O desafio social da gestão: a contribuição das ciências sociais. In: 
Bendassolli, P. F.; \& Soboll, L. A. P. (Orgs). Clínicas do Trabalho: Novas perspectivas para compreensão do trabalho na atualidade.São Paulo: Atlas, p. 110-131.

Cruz, V. A. G. da. (2009). Metodologia da Pesquisa Científica: Administração VI. São Paulo: Pearson Prentice Hall.

Dejours, C. (1989) (2009) (1-10 reimpr.). Trabalho e saúde mental: da pesquisa à ação. In: Dejours, C., Abdoucheli, E., \& Jayet, C. (Orgs). Psicodinâmica do trabalho: contribuições da escola dejouriana à análise da relação prazer, sofrimento e trabalho. São Paulo: Atlas, p. 45-65.

Dejours, C. (2004). Subjetividade, trabalho e ação. Production, 14(3), 27-34. DOI: https://dx.doi.org/10.1590/S010365132004000300004.

Dejours, C. (2004a). A Metodologia em Psicopatologia do Trabalho. In: Lancman, S., \& Sznelwar, L.I. Christophe Dejours Da Psicopatologia à Psicodinâmica do Trabalho. Rio de Janeiro: Ed. Fiocruz, Brasília: Paralelo, p.105-126.

Dejours, C. (2007) (7-8 reimpr.). A banalização da injustiça social. Trad. Luiz Alberto Monjardim. Rio de Janeiro: Editora FGV.

Dejours, C. (2008). Trabalho, tecnologia e organização: avaliação do trabalho submetida à prova do real. In: Sznelwar, L. I., \& Mascia, F. L. (Orgs.) Cadernos de $T T O, n^{\circ}$ 2. São Paulo: Blucher.

Enriquez, E. (2006). O homem do século XXI: sujeito autônomo ou indivíduo descartável. RAE-eletrônica, 5(1), Art. 10. Recuperado em

http://www.scielo.br/pdf/raeel/v5n1/29568. pdf.

Foucault, M. (1995). O sujeito e o poder In: Dreyfus, H., \& Rabinow, P. Michel Foucault: uma trajetória filosófica: para além do estruturalismo e da hermenêutica. Rio de Janeiro: Forense Universitária.

Gagnebin, J. M. (2012). Prefácio: Walter Benjamin ou a história aberta. In: Magia e Técnica, Arte e Política. Ensaios sobre literatura e história da cultura. Obras Escolhidas I. São Paulo: Brasiliense.

Gaulejac, V. de (2007). Gestão como doença social: ideologia, poder gerencialista $e$ fragmentação social. Trad. Ivo Storniolo. Aparecida/SP: Ideias \& Letras.

Gaulejac, V de (2011). A NGP: a Nova Gestão Paradoxal. In: Bendassoli, P. F., \& Soboll, L. A. P. (Orgs.). Clínicas do trabalho: novas perspectivas para compreensão do trabalho na atualidade. São Paulo: Atlas, p. 84-98.

Gernet, I., \& Dejours, C. (2011). Avaliação do trabalho e reconhecimento. In: Bendassoli, P. F., \& Soboll, L. A. P. (Orgs.). Clínicas do trabalho: novas perspectivas para compreensão do trabalho na atualidade. São Paulo: Atlas, p. 61-70.

Harvey, D. (1992). Condição Pós-moderna: uma pesquisa sobre a origens da mudança cultural. São Paulo: Loyola.

Jost, R., Fernandes, B., \& Soboll, L. A. (2014). A subjetividade do trabalhador nos diferentes modelos de gestão. In: Soboll, L. A., \& Ferraz, D. L. S. (Orgs.). Gestão de pessoas: armadilhas da organização do trabalho. São Paulo: Atlas, p. 3-15.

Merlo, A. R. C.; Lapis, N. L. (2007). A saúde e os processos de trabalho no capitalismo: reflexões na interface da psicodinâmica do trabalho e da sociologia do trabalho. Revista Psicologia \& Sociedade; 19 (1): 61-68. Recuperado em: http://www.lume.ufrgs.br/bitstream/handle/ 10183/20503/000613661.pdf?sequence $=1 \&$ locale $=$ pt_BR.

Merlo, A. R. C.; Mendes, A. M. B.(2009). Perspectivas do uso da psicodinâmica do trabalho no Brasil: teoria, pesquisa e ação. Cadernos de Psicologia Social do Trabalho; 12(2), 141-156. DOI: http://dx.doi.org/10.11606/issn.19810490.v12i2p141-156.

Motta, F. C. P.; Vasconcelos, I. F. G. de. (2006) (3). Teoria Geral da Administração. São Paulo: Cengage Learning.

Robbins, S. P.; Coulter, M. (1998) (5). Administração. Rio de Janeiro: PrenticeHall do Brasil. 
Seligmann-Silva, E. (2011) (1). Trabalho $e$ desgaste mental: o direito de ser dono de si mesmo. São Paulo: Cortez.

Taylor, F. W. (1995). Princípios de administração científica. Trad. Arlindo Vieira Ramos. São Paulo: Atlas.

Traesel, E. S., \& Merlo, A. R. C. (2014). "Somos sobreviventes": vivências de servidores públicos de uma instituição de seguridade social diante dos novos modos de gestão e a precarização do trabalho na reforma gerencial do serviço público. Cadernos de Psicologia Social do Trabalho, 17(2), 224-238. Recuperado em 10 de maio de 2017, de http://pepsic.bvsalud.org/scielo.php?script= sci_arttext\&pid=S1516$37172014000300006 \& \operatorname{lng}=$ pt\&tlng $=$ pt.

Weber, L.; Grisci, C. L. I. (2010). Trabalho, gestão e subjetividade: dilemas de chefias intermediárias em contexto hospitalar.

Cad. EBAPE.BR, Rio de Janeiro, 8(1), p.

53-70. DOI:

http://dx.doi.org/10.1590/S1679-

$\underline{39512010000100005}$.

Dados sobre os autores:

- Elisangela Carpenedo de Mattos é graduada em Psicologia pela Faculdade da Serra Gaucha (2013). Mestre em Psicologia Social e Institucional pela UFRGS (2016) e doutoranda de Psicologia Social e Institucional na UFRGS. Integrante do Laboratório de Psicodinâmica do Trabalho PPGPSI/UFRGS. Atualmente realizando pesquisas na área de Psicodinâmica do Trabalho, bem como submissão de projeto de atuação na mesma área junto aos sindicatos dos trabalhadores do Vale do Caí.

- Álvaro Roberto Crespo Merlo é médico do Trabalho, Especialista em Saúde Pública pela Université Paris I (Panthéon-Sorbonne) em 1979, Doutor em Sociologia pela Université Paris VII (Denis Diderot) em 1996. Atualmente é Professor Titular da Universidade Federal do Rio Grande do Sul, atua na Faculdade de Medicina, no Programa de Pós-Graduação em Psicologia Social e Institucional da UFRGS e é Professor MédicoAssistente do Hospital de Clínicas de Porto Alegre, no Serviço de Medicina Ocupacional/Ambulatório de Doenças do Trabalho e na Residência em Medicina do Trabalho. Atua na área de Psicologia, com ênfase em Psicodinâmica e Clínica do Trabalho e na área da Medicina, com ênfase em Medicina do Trabalho. Líder do Grupo de Pesquisa Laboratório de Psicodinâmica do Trabalho da UFRGS. 